\title{
Isotopic variation in Semail Ophiolite lower crust reveals crustal-level melt aggregation
}

\author{
M.N. Jansen ${ }^{1,2 *}$, C.J. Lissenberg ${ }^{1}$, M. Klaver ${ }^{3}$, S.J. de Graaff ${ }^{2,4}$ \\ J.M. Koornneef ${ }^{2}$, R.J. Smeets ${ }^{2}$, C.J. MacLeod ${ }^{1}$, G.R. Davies ${ }^{2}$
}

OPEN ACCESS

Abstract

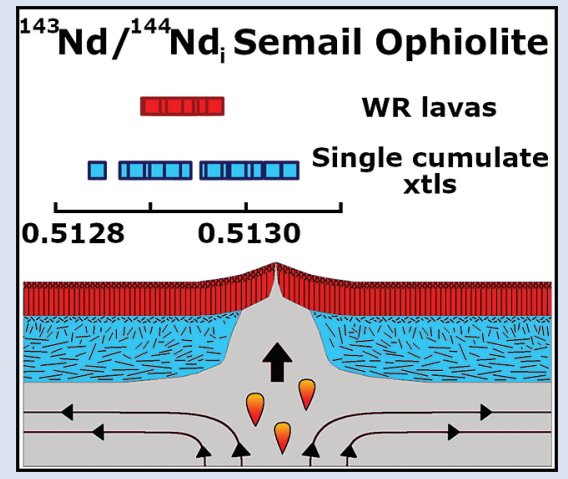

The scale and magnitude of compositional heterogeneity in the mantle has important implications for the understanding of the evolution of Earth. Heterogeneity of the upper mantle is often evaluated based on mid-ocean ridge basalt compositions, despite their homogenisation prior to eruption. In this study we present $\mathrm{Nd}$ and $\mathrm{Sr}$ isotope data obtained by micro-drilling single plagioclase and clinopyroxene crystals in gabbroic cumulates of the Semail Ophiolite (Oman) and show that mantle source variability is better preserved in the lower crust than in the extrusive suite. Analysis of sub-nanogram quantities of $\mathrm{Nd}$ in plagioclase revealed a range in ${ }^{143} \mathrm{Nd} /{ }^{144} \mathrm{Nd}_{\mathrm{i}}$ in the Wadi Abyad crustal section that is three times greater than recorded in the extrusive suite. The isotopic variability is preserved in plagioclase, whereas clinopyroxene is isotopically homogeneous. These data imply that the mantle is heterogeneous on the scale of melt extraction, and that a significant proportion of homogenisation of erupted melts occurs in the oceanic crust, not the mantle.

Received 15 April 2018 | Accepted 10 October 2018 | Published 5 November 2018

\section{Introduction}

Planetary differentiation and plate tectonics have led to marked compositional heterogeneity in Earth's mantle. Quantification of the scale and magnitude of mantle heterogeneity has important implications for the understanding of these processes and is one of the major challenges in geochemistry. Because the mantle cannot be sampled directly, this problem remains unresolved. Mid-ocean ridge basalts (MORB) are the most voluminous magmatic rocks on Earth, continually resurfacing two-thirds of the planet on an approximately 200 Myr timescale. They form through decompression melting of the upper mantle and typically undergo partial crystallisation in crustal magma chambers before being erupted onto the seafloor (e.g., Klein and Langmuir, 1987). Long-lived radiogenic isotopes are insensitive to crystallisation processes and are robust mantle source tracers. Many studies have therefore focused on the isotopic composition of MORB to assess alongridge mantle heterogeneity (e.g., Zindler et al., 1979). Magmatic processes at mid-ocean ridges, however, act to homogenise discrete magma batches (e.g., Rubin and Sinton, 2007), thus obscuring variability at the scale of melt extraction. Homogenisation of isotopic variability is particularly common at fast-spreading ridges, where higher melt production enhances magma mixing and reduces mantle-related variation in MORB compositions (Rubin and Sinton, 2007). Melt batch-scale heterogeneity is partially preserved in phenocrysts and their melt inclusions, which are believed to record unaggregated melt compositions (e.g., Lange et al., 2013). This suggests that lower crustal cumulates potentially record a greater isotopic variability than their extrusive counterparts.

Explicit consideration for the scale of sampling is essential for a full understanding of the lower oceanic crust due to the presence of significant compositional heterogeneity at scales ranging from millimetres to hundreds of metres (e.g., Lissenberg et al., 2013; Coogan, 2014). Whole rock geochemical analyses cannot resolve sample- or crystal-scale variations. Isotopic heterogeneity within individual minerals is to be expected if crystal growth spans replenishment and magma mixing episodes (Davidson and Tepley, 1997; Lange et al., 2013). Furthermore, whole rock isotopic data may mask heterogeneity if overgrowth on cumulus minerals and/or intercumulus minerals crystallised from isotopically distinct migrating interstitial melts (Yang et al., 2013).

\footnotetext{
School of Earth and Ocean Sciences, Cardiff University, Cardiff, United Kingdom

Faculty of Science, Vrije Universiteit, Amsterdam, the Netherlands

School of Earth Sciences, University of Bristol, Wills Memorial Building, Queens Road, Bristol BS8 1RJ, United Kingdom

Department of Analytical and Environmental Geochemistry, Vrije Universiteit Brussel, Brussels, Belgium

Corresponding author (e-mail: JansenMN@cardiff.ac.uk)
} 
a)

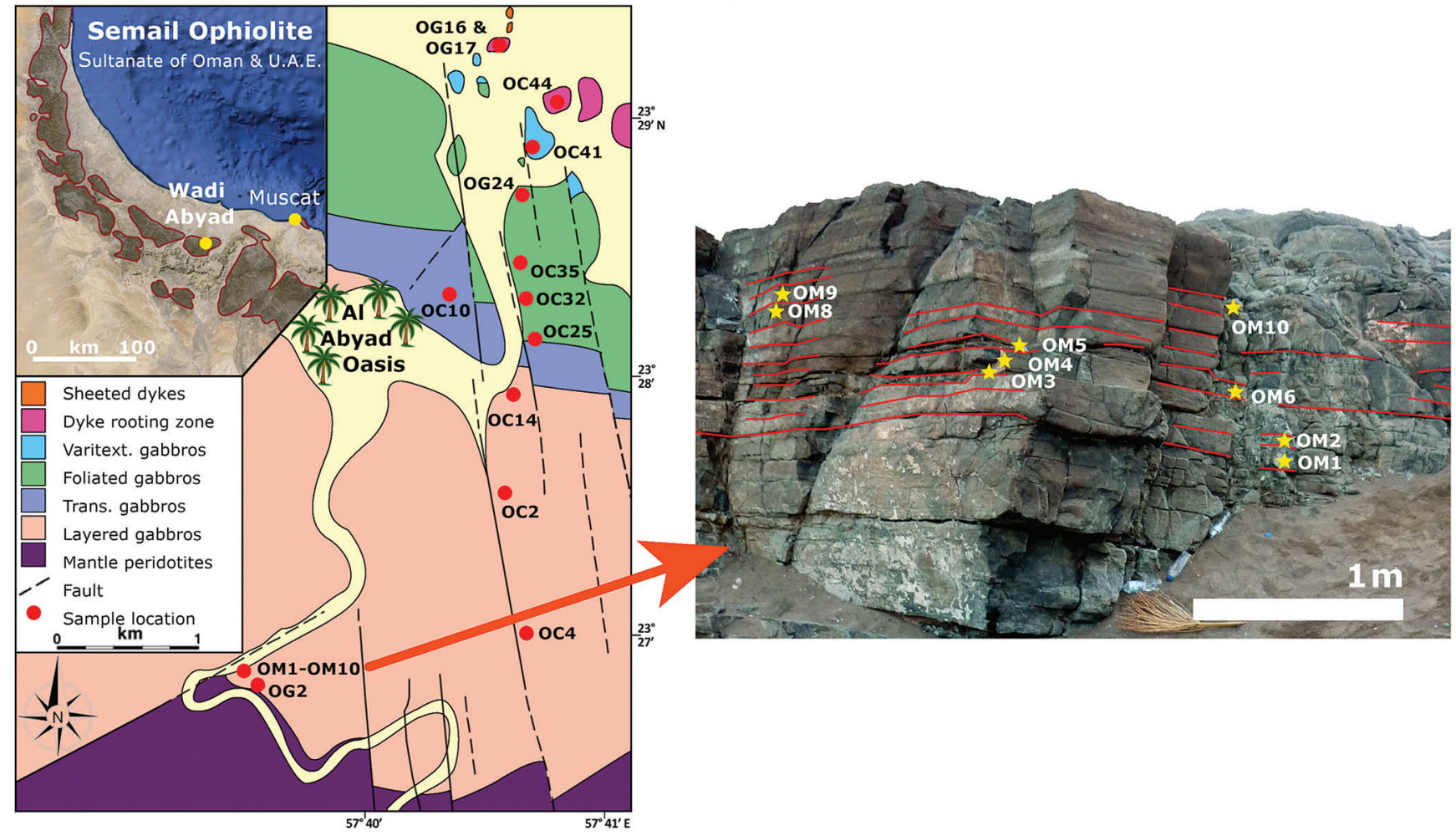

Figure 1 (a) Geological map of the lower crustal section at Wadi Abyad, in the Semail Ophiolite, Oman, with sample locations indicated (after MacLeod and Yaouancq, 2000; sample names were shortened by omitting the numerals ' $95^{\prime}$ ' preceding the letters 'OC' and 'OG' and '14' preceding 'OM'). (b) An outcrop at the base of the layered gabbros was sampled at $\sim 15 \mathrm{~cm}$ intervals (one sample per modal layer).

Due to its inaccessibility, oceanic crust is often studied using on-land analogues such as the $96 \mathrm{Ma}$ Semail Ophiolite in Oman and the UAE (Nicolas, 1989; Rioux et al., 2013). Although the Semail Ophiolite may have formed in a subduction-related setting (MacLeod et al., 2013), its mode of formation and isotopic signature is comparable to MORB (Godard et al., 2006) and therefore an ideal location for this study. A micro-sampling technique for plagioclase and clinopyroxene crystals allowed isotopic analyses of single mineral grains for which the textural context and geochemical composition were known and avoided averaging isotopic variations within a sample.

\section{Geological Setting and Methods}

The Semail Ophiolite lower crust at Wadi Abyad consists of a $\sim 1700 \mathrm{~m}$ thick sequence of modally layered gabbros, overlain by non-layered, steeply-foliated gabbros $(\sim 650 \mathrm{~m})$ and $\sim 150 \mathrm{~m}$ of varitextured gabbros and a 'dyke rooting zone' transition into the base of a sheeted dyke complex (MacLeod and Yaouancq, 2000). Thirteen gabbros and olivine-gabbros spanning the entire lower crustal stratigraphy were sampled at an average interval of $\sim 200 \mathrm{~m}$, complemented with nine sampled modal layers ( $15 \mathrm{~cm}$ thick) from a single outcrop near the base of the layered gabbros (Fig. 1). Major and trace element data collected from thick sections by EMP and LA-ICPMS (Supplementary Information, Table S-4e) were combined with EDS-SEM major element mapping of polished rock slabs to select domains most suitable for micro-sampling in the latter. Single crystal isotopic analyses ( $\mathrm{Nd}$ and $\mathrm{Sr}$ in plagioclase; $\mathrm{Nd}$ in clinopyroxene) were performed on material obtained by micro-drilling individual crystals. The amount of Nd recovered ranged between $\sim 1-5 \mathrm{ng}$ in clinopyroxene and $\sim 0.1-0.5 \mathrm{ng}$ in plagioclase, while $~ 500 \mathrm{ng}$ Sr was obtained from plagioclase. Plagioclase samples were spiked with a ${ }^{149} \mathrm{Sm}-{ }^{150} \mathrm{Nd}$ mixed-spike prior to digestion for
$\mathrm{Sm} / \mathrm{Nd}$ isotope dilution analysis. Chemical separation for $\mathrm{Sr}, \mathrm{Nd}$ and $\mathrm{Sm}$ was performed using standard ion exchange techniques and samples were measured on a Thermo Scientific Triton Plus thermal ionisation mass spectrometer (TIMS), using $10^{13} \Omega$ amplifiers for the measurement of Sm (50-250 $\mathrm{pg}$ ) and $\mathrm{Nd}$ in the plagioclase samples. Isotope ratios were age-corrected to $96 \mathrm{Ma}$ (subscript " $\mathrm{i}$ "; Rioux et al., 2013). The reproducibility (2 SD) of ${ }^{143} \mathrm{Nd} /{ }^{144} \mathrm{Nd}$ for BCR-2 reference material is $161 \mathrm{ppm}$ for aliquots of $0.15-0.34 \mathrm{ng} \mathrm{Nd}$ and 82 ppm for aliquots of 1.9-2.6 ng Nd. A detailed description of the methods and results for internal and external standards is provided in the Supplementary Information.

\section{Results}

Plagioclase and clinopyroxene crystals have ${ }^{143} \mathrm{Nd} /{ }^{144} \mathrm{Nd}_{\mathrm{i}}$ typical of MORB, with values ranging from 0.512844 to 0.513046 (Figs. 2 and 3, Supplementary Information, Table S-4a-d). Clinopyroxene samples reveal an almost uniform $\mathrm{Nd}$ isotope composition, with a range of $225 \mathrm{ppm}$ and only two samples, from the foliated gabbros and dyke rooting zone, are outside error (by $10 \mathrm{ppm}$ ); the ppm notation here indicating the range relative to the average ${ }^{143} \mathrm{Nd} /{ }^{144} \mathrm{Nd}_{\mathrm{i}}$ of the dataset (0.512936).

Plagioclase samples display a greater range in $\mathrm{Nd}$ isotope composition, $395 \mathrm{ppm}$, with the lowest values outside error of the highest values by up to $88 \mathrm{ppm}$ (Fig. 2). This range is well in excess of the variation found in the extrusive suite of the entire Semail Ophiolite (whole rock; $134 \mathrm{ppm}$ ). It is also significantly larger than existing whole rock and mineral separate data for the lower crust (123 ppm). It is, however, comparable to the range found in gabbroic cumulates in the Maqsad mantle harzburgites (whole rock; $414 \mathrm{ppm}$ ), which are interpreted to be individual melt batches within a fossil mantle diapir (Benoit et al., 1996; Fig. 4, all data sources in figure caption). 
a) Clinopyroxene

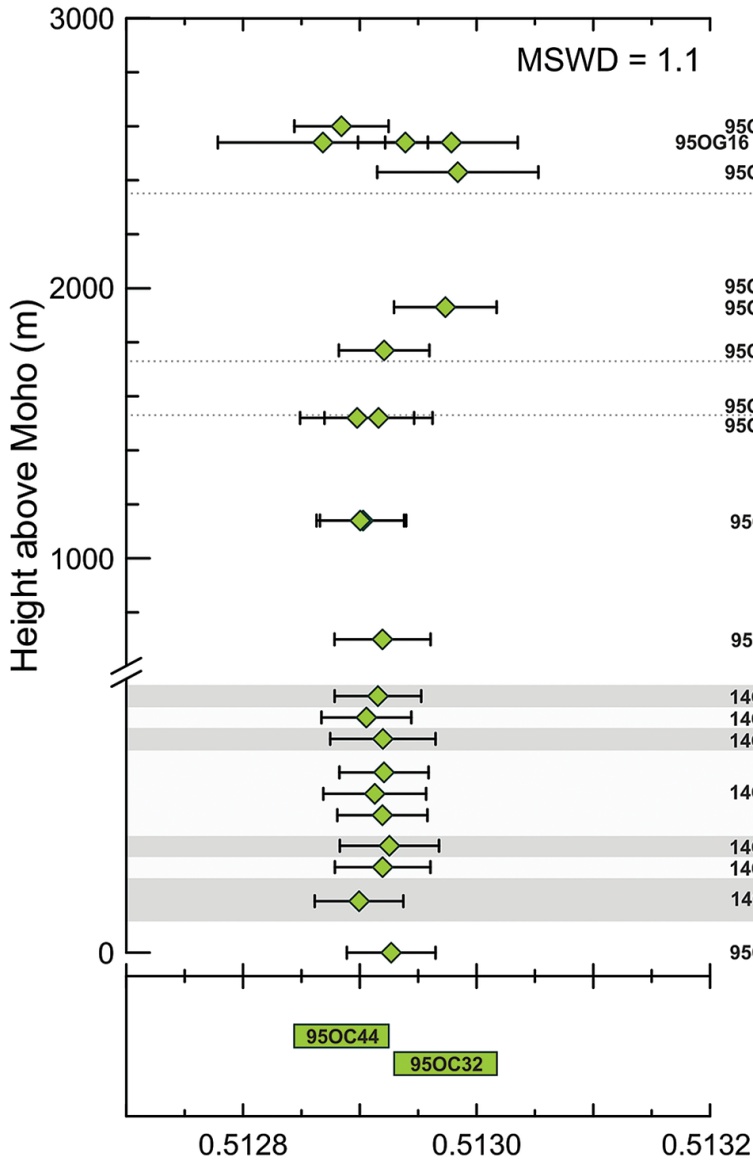

b) Plagioclase

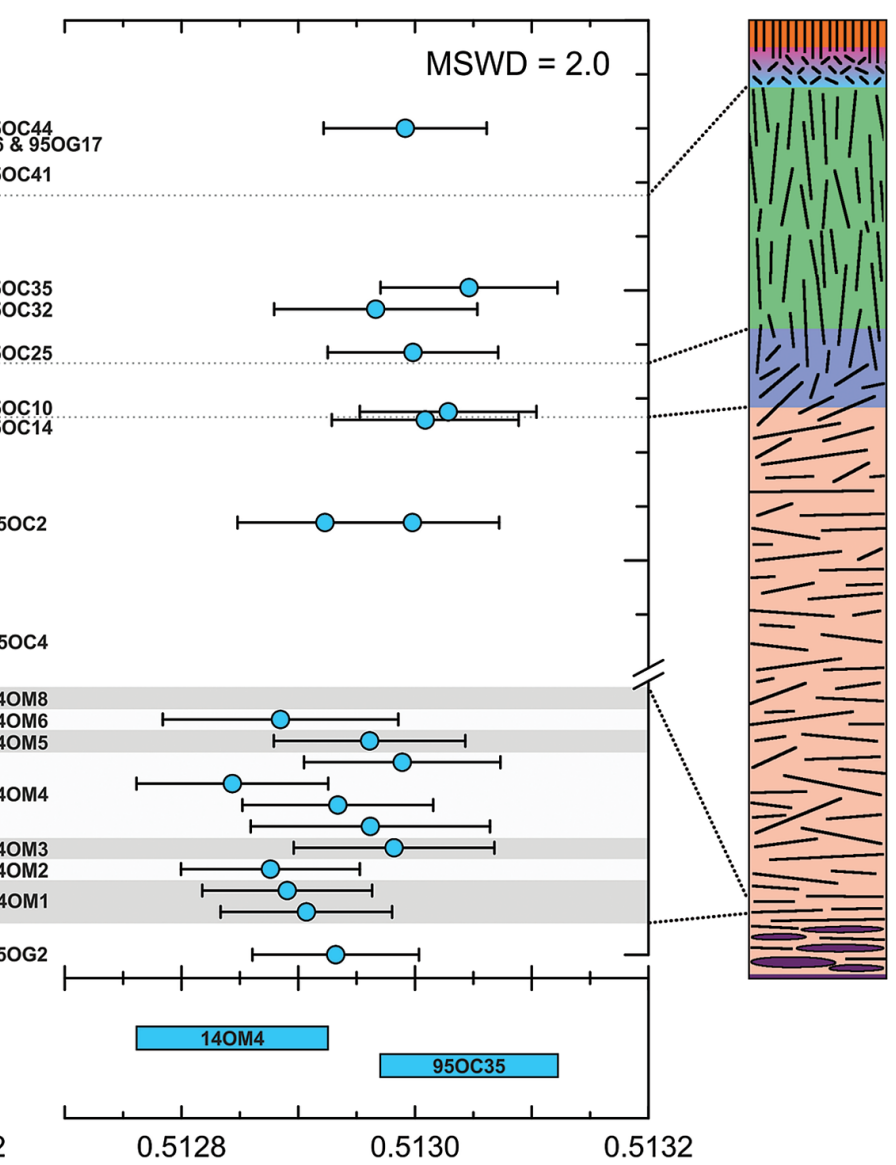

${ }^{143} \mathrm{Nd} /{ }^{144} \mathrm{Nd}_{\mathrm{i}}$

Figure 2 Age-corrected ${ }^{143} \mathrm{Nd} /{ }^{144} \mathrm{Nd}$ of (a) single clinopyroxene and (b) plagioclase crystals in the Abyad section. Clinopyroxene has a near uniform composition whereas plagioclase shows variability outside analytical uncertainty. Grey and white alternating bars at the base of the section indicate the individual modal layers of the sampled layered gabbro outcrop (not to scale). Coloured bars at the bottom of the figure represent the uncertainty for the two most extreme samples.

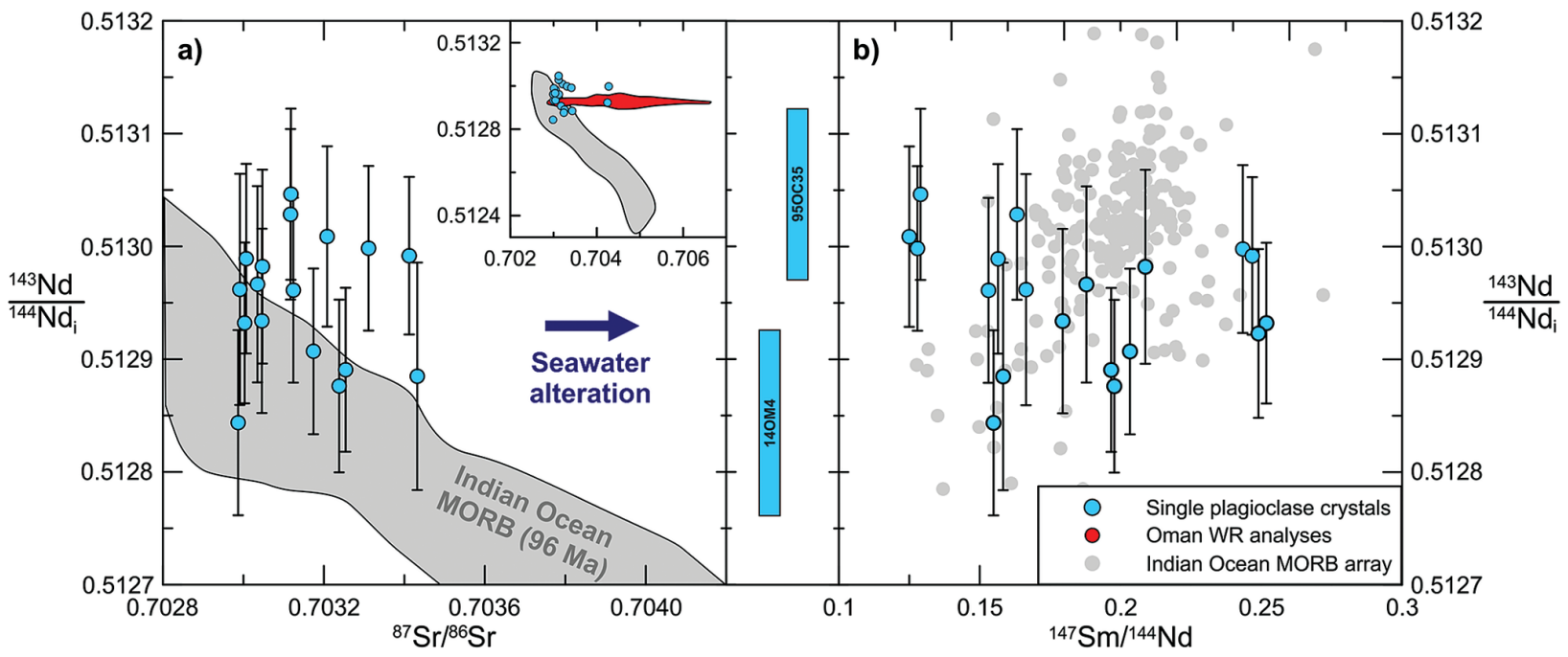

Figure 3 (a) Age-corrected ${ }^{143} \mathrm{Nd} /{ }^{144} \mathrm{Nd}_{i}$ and ${ }^{87} \mathrm{Sr} /{ }^{86} \mathrm{Sr}$ compositions of plagioclase samples. Indian Ocean MORB data from the PetDB database and age-corrected to $96 \mathrm{Ma}$ using model Sm/Nd and Rb/Sr ratios for depleted MORB mantle (Workman and Hart, 2005). The ranges of whole rock age-corrected $\mathrm{Sr}$ and $\mathrm{Nd}$ isotope analyses of the plutonic and extrusive series of the Semail Ophiolite are shown in the inset (McCulloch et al., 1980; Godard et al., 2006; Rioux et al., 2012, 2013; de Graaff, 2016). (b) Age-corrected ${ }^{143} \mathrm{Nd} /{ }^{144} \mathrm{Nd}$; and ${ }^{147} \mathrm{Sm} /{ }^{144} \mathrm{Nd}$ ratios show no correlation, whereas the present day Indian Ocean MORB array, shown for comparison, displays a broad positive correlation. Coloured bars in the centre panel represent the uncertainty in ${ }^{143} \mathrm{Nd} /{ }^{144} \mathrm{Nd}_{\mathrm{i}}$ for the two most extreme samples. 
The plagioclase $\mathrm{Nd}$ data $(\mathrm{n}=19)$ yield a mean square weighted deviation (MSWD $=2.0$ ) that is significantly greater than the critical value (1.7; following Wendt and Carl, 1991; see Supplementary Information), meaning that the probability that the data form a single, normally distributed population is $<5 \%$. We therefore argue that the observed ${ }^{143} \mathrm{Nd} /{ }^{144} \mathrm{Nd}_{i}$ heterogeneity in plagioclase is statistically significant and represents a primary feature. The clinopyroxene data $(n=22)$ show an MSWD that is smaller than the critical MSWD (1.1 versus 1.6, respectively), implying that the clinopyroxene data constitute a statistically homogeneous population at the current level of precision.

There is no discernible stratigraphic trend in plagioclase isotopic composition and the samples record a relatively large range in ${ }^{147} \mathrm{Sm} /{ }^{144} \mathrm{Nd}$ ratios $(0.13-0.25)$ that does not correlate with ${ }^{143} \mathrm{Nd} /{ }^{144} \mathrm{Nd}_{\mathrm{i}}$ (Fig. 3). With the exception of two samples, $\mathrm{Nd}$ and $\mathrm{Sr}$ isotope ratios in plagioclase crystals are closer to the MORB array than whole rock isotopic analyses (red field in Fig. 3). It is difficult to interpret the variability of strontium isotopes in plagioclase purely in terms of mantle source as seawater alteration is known to elevate ${ }^{87} \mathrm{Sr} /{ }^{86} \mathrm{Sr}$ without affecting ${ }^{143} \mathrm{Nd} /{ }^{144} \mathrm{Nd}$ (McCulloch et al., 1980). The limited range observed in the micro-drilled ${ }^{87} \mathrm{Sr} /{ }^{86} \mathrm{Sr}$ compositions potentially records less extensive seawater alteration but we cannot disentangle minor alteration from source heterogeneity.

\section{Discussion}

Our data represent the first micro-drilled $\mathrm{Nd}$ isotope mineral analyses for lower ocean crustal rocks and provide constraints on both ocean crustal and mantle processes. Compared to previous whole rock analyses of plutonic rocks, single plagioclase crystals record a larger $\mathrm{Nd}$ isotope variability and are thus much more suitable for studying the full extent of isotopic variability in the lower oceanic crust. The similarity of the observed Nd isotope range in plagioclase to the gabbros from the Maqsad diapir (Fig. 4), taken to represent individual melt batches in upwelling mantle (Benoit et al., 1996), suggests that the lower crust preserves the heterogeneity of melt batches at a mineral scale. This implies that the upper mantle is compositionally heterogeneous at the scale of melt extraction (e.g., Lange et al., 2013), and that the melt extraction process did not fully homogenise melts. The isotopic variability in whole rock analyses of the overlying dykes and lavas, representing fully aggregated and erupted melts, is limited compared to plagioclase in the lower crust (Fig. 4) and indicates that the substantial mixing and homogenisation required to produce MORB takes place in the crust. Previous comparisons of upper crustal basalts to whole rock analyses of plutonic rocks led to a substantially different conclusion as illustrated in Figure 4 (e.g., Coogan, 2014). The whole rock data alone suggest the upper
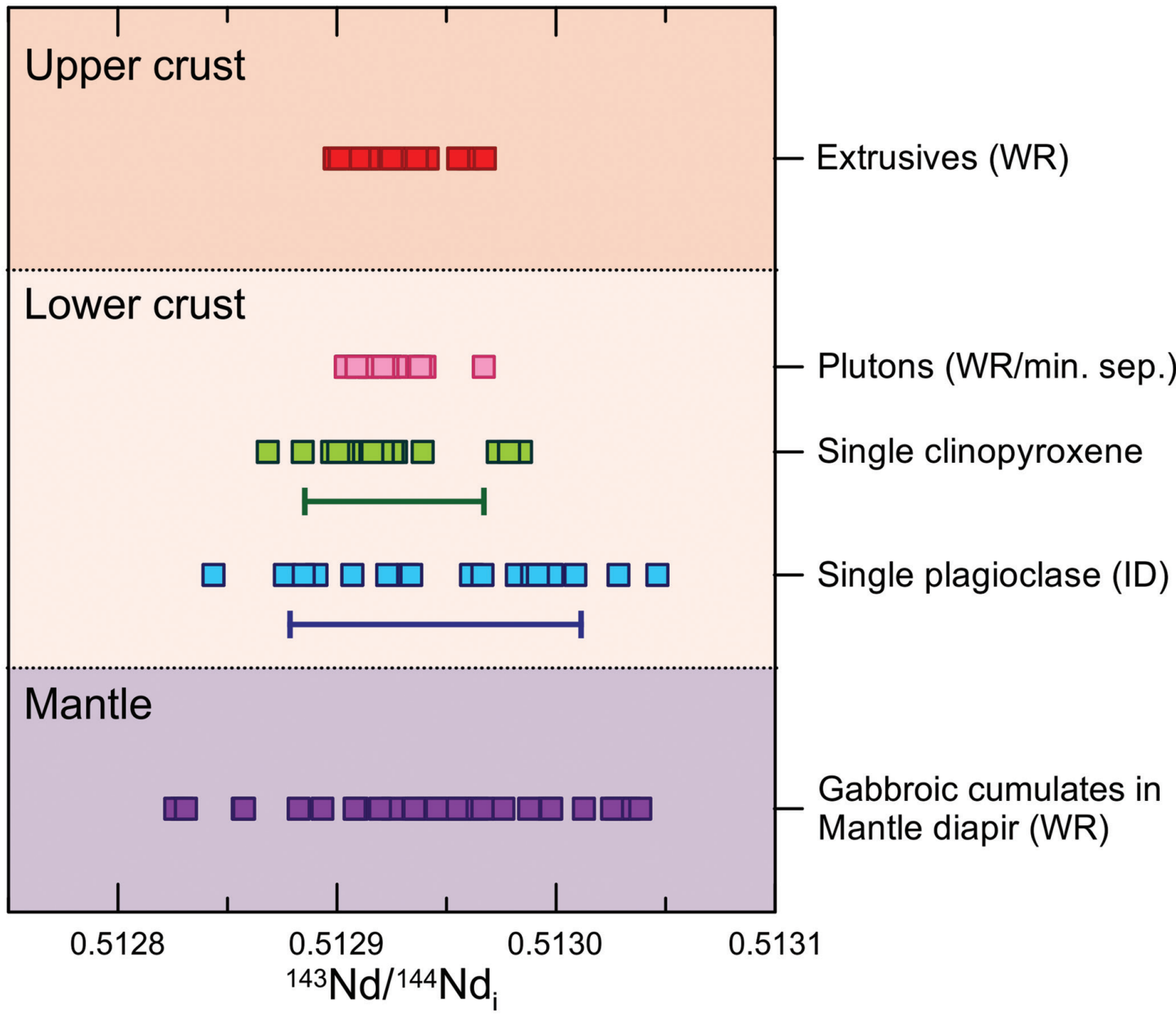

Figure 4 Comparison of the ranges in Nd isotopes found in this study with previous results of the Semail Ophiolite (McCulloch et al., 1980; Benoit et al., 1996; Godard et al., 2006; Rioux et al., 2012, 2013; de Graaff, 2016). Range for repeated analyses of BCR-2 reference material is indicated by the green (1.9-2.6 $\mathrm{ng} \mathrm{Nd}$ ) and blue (0.15-0.34 $\mathrm{ng} \mathrm{Nd}$ ) bars (displayed at an arbitrary position on the $\mathrm{x}$-axis). 
and lower crust formed from melts that were homogenised to similar extents. Our findings also contrast with Koga et al. (2001) who concluded that trace element variability in the Moho transition zone in the Semail Ophiolite is comparable to that in the upper crustal sheeted dyke complex and lavas and that mixing must have taken place predominantly in the mantle.

This study demonstrates that the approach of using mineral trace element ratios alone to study source compositions can be problematic. We find that plagioclase $\mathrm{Sm} / \mathrm{Nd}$ does not correlate with ${ }^{143} \mathrm{Nd} /{ }^{144} \mathrm{Nd}_{\mathrm{i}}$ (the time integrated $\mathrm{Sm} / \mathrm{Nd}$ ), whereas a positive correlation would be expected if $\mathrm{Sm} / \mathrm{Nd}$ is inherited from a mantle source (Fig. 3). Several other processes can affect $\mathrm{Sm} / \mathrm{Nd}$, such as degree of mantle melting, fractional crystallisation, melt replenishment $\left(\mathrm{O}^{\prime} \mathrm{Neill}\right.$ and Jenner, 2012), melt-rock reactions (Lissenberg and MacLeod, 2016) and variable partition coefficients due to changes in pressure, An \%, $\mathrm{pH}_{2} \mathrm{O}$ and melt composition (Bédard, 2006). Hence, it is difficult to interpret a source signature from plagioclase trace element compositions. Since Nd isotope ratios are not fractionated by these processes, they are uniquely suited for investigating sources of mantle derived melt.

The contrast in ${ }^{143} \mathrm{Nd} /{ }^{144} \mathrm{Nd}_{\mathrm{i}}$ variability between clinopyroxene (homogeneous) and plagioclase (heterogeneous) can have multiple causes. The first is sub-solidus diffusion of REE. This unlikely to be responsible for homogenisation, however, since $\mathrm{Nd}$ diffusion coefficients of clinopyroxene are two orders of magnitude lower than plagioclase (van Orman et al., 2001; Cherniak, 2003) and modelling shows that diffusion would primarily affect plagioclase rather than clinopyroxene for conditions prevalent in the lower oceanic crust (Coogan and O’Hara, 2015).

The second is a crystallisation sequence of plagioclase before clinopyroxene during progressive magma mixing and associated homogenisation. Textures of Wadi Abyad gabbros are granular to intergranular, with an apparent olivine -> plagioclase $\rightarrow$ clinopyroxene crystallisation sequence. The absence of troctolites in the section, however, may indicate a near simultaneous saturation of plagioclase and clinopyroxene (Thomas, 2003). Furthermore, moderate textural re-equilibration during slow cooling may obscure primary textures and make it difficult to distinguish co-crystallisation from sequential crystallisation (MacLeod and Yaouancq, 2000).

Finally, reactive porous flow of interstitial melts may be responsible for isotopic homogenisation in clinopyroxene. Migration of late stage melts by porous flow is pervasive throughout the entire lower crust (Lissenberg et al., 2013; Lissenberg and MacLeod, 2016). Clinopyroxene and plagioclase in gabbros at Wadi Abyad show features that have been ascribed to reactive porous flow, including an up-section increase in enrichment and fractionation of elements proportional to their incompatibility (e.g., La/Nd and $\mathrm{Ce} / \mathrm{Y}$ ) and trace element disequilibrium between coexisting plagioclase and clinopyroxene (Lissenberg and MacLeod, 2016). If the migrating interstitial melts are isotopically homogeneous, as seems likely, melt-crystal reaction can conceivably homogenise isotopic variation in the lower crust. It is currently unclear, however, whether clinopyroxene is more sensitive to melt-rock reactions than plagioclase, as would be implied by the data: further work on this subject is required.

This work demonstrates that isotopic analysis of single grains in plutonic rocks has great potential to study the scale of mantle heterogeneity and the nature of crustal processes. By establishing that greater variability exists in the lower crust than in the erupted lavas of the Semail Ophiolite, we have shown that isotopic studies of whole rock MORB mask the full scale and extent of compositional heterogeneity of the mantle source. Micro-sampling successfully avoids interstitial grains and domains most affected by alteration (i.e. crystal rims) and, with the latest generation of sensitive amplifier technology, yields enough material to identify isotopic variability. Future research should employ these techniques to investigate further the presence of stratigraphic trends on various scales and isotopic disequilibrium between clinopyroxene and plagioclase. A better understanding of the variability of isotopic composition in the lower oceanic crust has implications for the location of melt emplacement and the location and extent of magma mixing at oceanic spreading centres, as well as the scale and magnitude of mantle heterogeneity.

\section{Acknowledgements}

The authors would like to thank Sergei Matveev and Jasper Berndt for their technical assistance with EMP and LA-ICPMS analyses. Chris Coath is thanked for his help with data treatment. Kathryn Goodenough, Michael Styles and David Schofield of the British Geological Survey are thanked for their help in the field. We wish to thank two anonymous reviewers and editor Cin-Ty Lee for their constructive comments that helped improve the manuscript.

Editor: Cin-Ty Lee

\section{Additional Information}

Supplementary Information accompanies this letter at http:// www.geochemicalperspectivesletters.org/article1827.

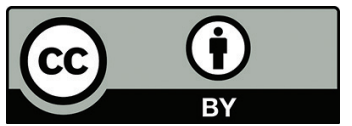

This work is distributed under the Creative Commons Attribution 4.0 License, which permits unrestricted use, distribution, and reproduction in any medium, provided the original author and source are credited. Additional information is available at http://www.geochemicalperspectivesletters.org/copyright-andpermissions.

Cite this letter as: Jansen, M.N., Lissenberg, C.J., Klaver, M., de Graaff, S.J., Koornneef, J.M., Smeets, R.J., MacLeod, C.J., Davies, GR.. (2018) Isotopic variation in Semail Ophiolite lower crust reveals crustal-level melt aggregation. Geochem. Persp. Let. 8, 37-42.

\section{References}

BÉDARD, J.H. (2006) Trace element partitioning in plagioclase feldspar. Geochimica et Cosmochimica Acta 70, 3717-3742.

Benoit, M., Polvé, M., Ceuleneer, G. (1996) Trace element and isotopic characterization of mafic cumulates in a fossil mantle diapir (Oman ophiolite). Chemical Geology 134, 199-214.

CherniaK, D.J. (2003) REE diffusion in feldspar. Chemical Geology 193, 25-41.

CoogAn, L.A. (2014) The Lower Oceanic Crust. In: Holland, H.D., Turekian, K.K. (Eds.) Treatise on Geochemistry. Second Edition, Elsevier, Oxford, 497-541.

COOGAN, L.A., O'HARA, M.J. (2015) MORB differentiation: In situ crystallization in replenished-tapped magma chambers. Geochimica et Cosmochimica Acta 158, 147-161.

DAVIDSON, J.P., TEPLEY, F.J. (1997) Recharge in volcanic systems: evidence from isotope profiles of phenocrysts. Science 275, 826-829.

Godard, M., Bosch, D., EINAUdi, F. (2006) A MORB source for low-Ti magmatism in the Semail ophiolite. Chemical Geology 234, 58-78.

De GraAfF, S. (2016) Did the Oman Ophiolite form above a subduction zone? Evidence from widespread later-stage intrusions in the Central and Southeastern Semail Ophiolite. MSc thesis, Vrije Universiteit Amsterdam, 42 pp. 
KLeIN, E.M., LANGMUIR, C.H. (1987) Global correlations of ocean ridge basalt chemistry with axial depth and crustal thickness. Journal of Geophysical Research: Solid Earth 92, 8089-8115.

KogA, K.T., Kelemen, P.B., Shimizu, N. (2001) Petrogenesis of the crustmantle transition zone and the origin of lower crustal wehrlite in the Oman ophiolite. Geochemistry, Geophysics, Geosystems 2, 2000 GC000132.

Lange, A.E., Nielsen, R.L., Tepley, F.J., Kent, A.J.R. (2013) Diverse Sr isotope signatures preserved in mid-oceanic-ridge basalt plagioclase. Geology 41, 279-282.

LissenberG, C.J., MacLeod, C.J. (2016) A Reactive Porous Flow Control on Mid-ocean Ridge Magmatic Evolution. Journal of Petrology 57, 2195-2220.

LissenberG, C.J., MacLeod, C.J., Howard, K.A., Godard, M. (2013) Pervasive reactive melt migration through fast-spreading lower oceanic crust (Hess Deep, equatorial Pacific Ocean). Earth and Planetary Science Letters 361, 436-447.

MacLeod, C.J., YaOUANCQ, G. (2000) A fossil melt lens in the Oman ophiolite: Implications for magma chamber processes at fast spreading ridges. Earth and Planetary Science Letters 176, 357-373.

MacLeod, C.J., LissenberG, C.J., Bibby, L.E. (2013) "Moist MORB" axial magmatism in the Oman ophiolite: The evidence against a mid-ocean ridge origin. Geology 41, 459-462.

McCulloch, M.T., Gregory, R.T., WasserburG, G.J., Taylor Jr, H.P. (1980) A neodymium, strontium, and oxygen isotopic study of the Cretaceous Samail ophiolite and implications for the petrogenesis and seawater-hydrothermal alteration of oceanic crust. Earth and Planetary Science Letters 46, 201-211.

Nicolas, A. (1989) Structures of ophiolites and dynamics of ocean lithosphere. Kluwer Academic Publishers, Dordrecht, 367 pp.

O'NeILL, H., JenNer, F.E. (2012) The global pattern of trace-element distributions in ocean floor basalts. Nature 491, 698-704.

Rioux, M., Bowring, S., Kelemen, P., Gordon, S., DudÁs, F., Miller, R. (2012) Rapid crustal accretion and magma assimilation in the Oman-U.A.E. ophiolite: High precision U-Pb zircon geochronology of the gabbroic crust. Journal of Geophysical Research: Solid Earth 117, B07201.

Rioux, M., Bowring, S., Kelemen, P., Gordon, S., Miller, R., Dudas, F. (2013) Tectonic development of the Samail ophiolite: High precision $\mathrm{U} \mathrm{Pb}$ zircon geochronology and Sm Nd isotopic constraints on crustal growth and emplacement. Journal of Geophysical Research: Solid Earth $118,2085-2101$.

Rubin, K.H., SinTON, J.M. (2007) Inferences on mid-ocean ridge thermal and magmatic structure from MORB compositions. Earth and Planetary Science Letters 260, 257-276.

THOMAs, R. M. (2003) Processes of lower crustal accretion beneath intermediate- to fast-spreading ocean ridges: constraints from the Wadi Abyad section of the Oman ophiolite. PhD thesis, Cardiff University, $497 \mathrm{pp}$.

VAN ORMAn, J., Grove, T., SHIMIZU, N. (2001) Rare earth element diffusion in diopside: influence of temperature, pressure, and ionic radius, and an elastic model for diffusion in silicates. Contributions to Mineralogy and Petrology 141, 687-703.

WENDT, I., CARL, C. (1991) The statistical distribution of the mean squared weighted deviation. Chemical Geology: Isotope Geoscience section 86, 275-285.

WORKMAN, R.K., HART, S.R. (2005) Major and trace element composition of the depleted MORB mantle (DMM). Earth and Planetary Science Letters 231, 53-72.

YAnG, S.H, Maier, W.D., Lahaye, Y., O’Brien, H. (2013) Strontium isotope disequilibrium of plagioclase in the Upper Critical Zone of the Bushveld Complex: evidence for mixing of crystal slurries. Contributions to Mineralogy and Petrology 166, 959-974.

Zindler, A., Hart, S.R., FreY, F.A., JAKObSSON, S.P. (1979) Nd and Sr isotope ratios and rare earth element abundances in Reykjanes Peninsula basalts evidence for mantle heterogeneity beneath Iceland. Earth and Planetary Science Letters 45, 249-262. 